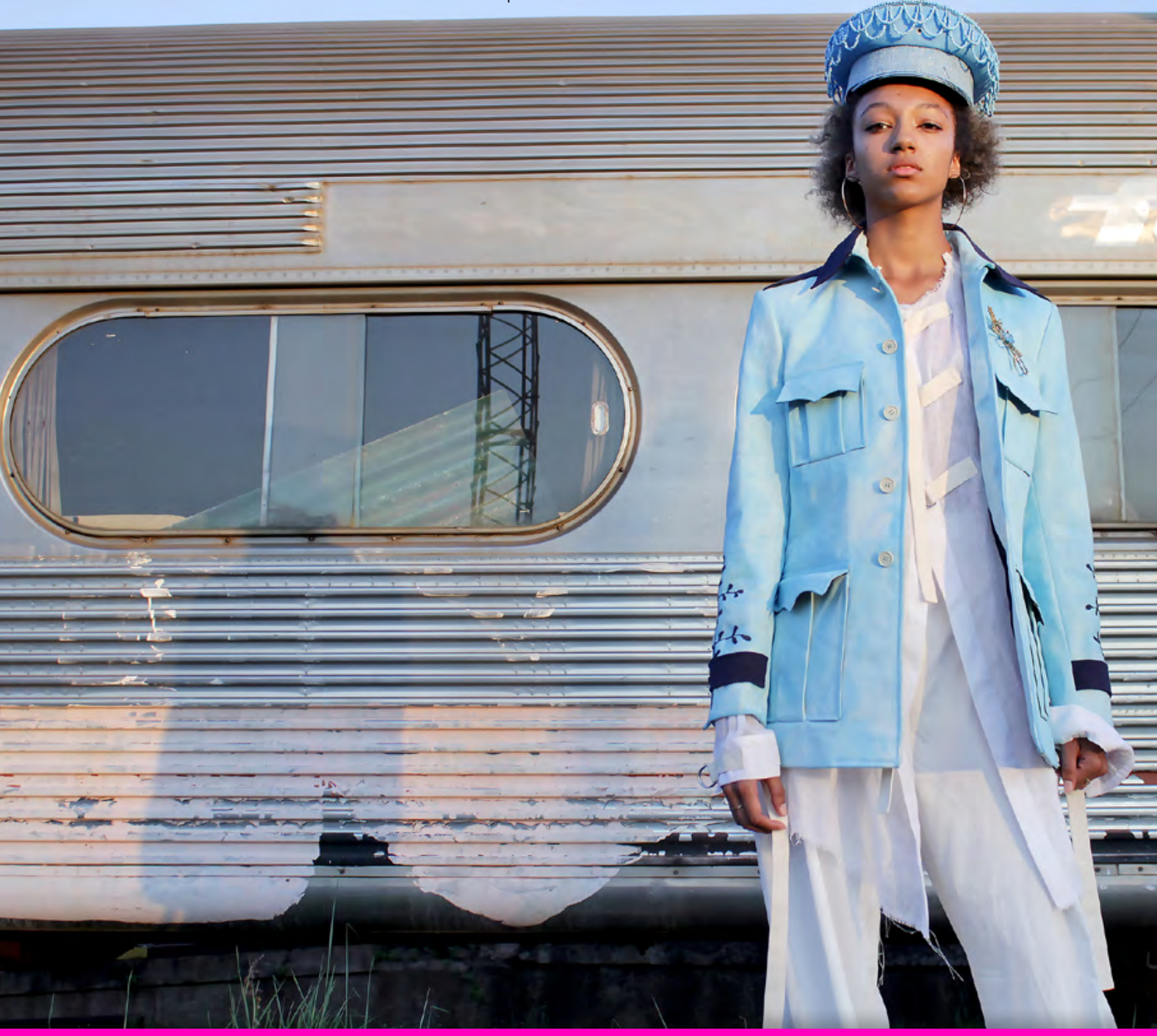

\title{
Compartilhamento do conhecimento no contexto da educação superior em moda: estudo de caso
}

Sharing of knowledge in the context of fashion college education: case study 


\section{[MARIA HELENA RIBEIRO DE CARVALHO]}

Mestre em Gestão do Conhecimento nas Organizações/Uem

E-mail: marihelenribeiro67@gmail.com

\section{[PAULA PIVA LINKE]}

Doutora em Ciência Ambiental/Unifamma

E-mail: paulapivalinke@gmail.com

\section{[LETICIA FLEIG DEL FORNO]}

Doutora em Educação/Unicesumar

E-mail: lefleig@gmail.com

\section{[PAULO MARCELO FERRARESI PEGINO]}

Doutor em Administração de Empresas/Unicesumar

E-mail: pferraresi@gmail.com

[resumo] 0 compartilhamento de saberes pessoais é uma ferramenta e uma prática da gestão do conhecimento que pode auxiliar em práticas docentes. Neste estudo buscou-se entender como ocorre o compartilhamento do conhecimento nas intervenções e práticas de ensino aplicadas na disciplina modelagem do vestuário entre os professores em um curso de ensino superior em moda. Utilizou-se como metodologia a pesquisa qualitativa com coleta de dados por meio de entrevistas semiestruturadas. Observouse que o compartilhamento do conhecimento se faz presente não somente na disciplina de modelagem, mas em todo o curso, no qual a prática de ensino envolve diferentes métodos e projetos com o intuito de melhorar a aprendizagem do aluno.

\section{[palavras-chave]}

\section{moda, modelagem, compartilhamento do} conhecimento.

[abstract] The sharing of personal knowledge is a tool and a practice of knowledge management that can assist in teaching practices. This study sought to understand how knowledge sharing occurs in the interventions and teaching practices applied in the clothing modeling discipline among professors in a Fashion college. Qualitative research with data collection through semi-structured interviews was used as methodology. It was observed that knowledge sharing is present not only in the modeling discipline, but throughout the course, in which teaching practice involves different methods and projects in order to improve student learning.

[keywords] fashion, clothing modeling, knowledge sharing. 
Introdução

Os primeiros cursos voltados ao desenho de moda e estilos, assim como os cursos superiores em moda, surgiram no Brasil a partir dos anos 1980. 0 intuito era formar profissionais capazes de atuar no setor têxtil (DELGADO, 2010). A partir desse período, vários outros cursos superiores em moda surgiram em muitos estados do país. No ano de 2004, o Ministério da Educação e Cultura - MEC vinculou a moda à área de conhecimento do design e os cursos de ensino superior em moda já existentes tiveram que readequar suas grades curriculares para atender as novas exigências.

Desde então, os cursos superiores voltados ao setor da moda vêm passando por grandes transformações, como afirma Delgado (2010), mudanças que se referem aos formatos dos cursos de graduação, sejam eles bacharelados ou tecnológicos. Para a autora, essas modificações visam expressar as novas necessidades do mercado em relação à capacitação dos futuros profissionais e ao papel das instituições de ensino superior (IES) nesse processo de formação.

Com o mercado globalizado, foi preciso avançar nos saberes sobre educação de modo que estes alcançassem a evolução tecnológica e as coerções impostas por uma realidade social saturada de informação. Pensando especificamente no ensino superior, o contexto contemporâneo no Brasil vem sendo marcado por diversas práticas que têm como objetivo popularizar o acesso à educação superior (FAZENDA, 2013). Ainda que a curva no gráfico do acesso à educação superior esteja em decadência, após ter atingido um ápice em termos de investimentos governamentais, o Brasil conta, atualmente, com um volume bastante significativo de instituições de ensino, sejam públicas ou privadas, as quais geram novas demandas e, entre elas, pode-se destacar a gestão do conhecimento (FAZENDA, 2013).

Em termos de conceituação, Cajueiro e Sicsú (2007) afirmam que existem diferentes linhas teóricas para a definição da gestão do conhecimento, ainda em processo de construção, apresentando diferentes perspectivas. Para Dalkir (2011), a gestão do conhecimento no ambiente organizacional tem relação com a cultura organizacional, interação entre os colaboradores, compartilhamento dos saberes individuais, codificação, arquivamento e aplicação do conhecimento organizacional.

Cabe destacar que não basta compreender a gestão do conhecimento e seus processos; considera-se importante refletir sobre como se dá o compartilhamento do conhecimento dentro das instituições de ensino superior. 0 compartilhamento do conhecimento é uma das etapas da gestão do conhecimento e ocorre como um processo social de aprendizagem, portanto, a interação das pessoas e o diálogo constante são indispensáveis (DALKIR, 2011). 
Partindo do pressuposto de que existe o compartilhamento do conhecimento nas práticas de ensino entre professores no ensino superior de moda, abordou-se o seguinte questionamento: como ocorre o compartiIhamento do conhecimento das práticas de ensino aplicadas na disciplina modelagem do vestuário entre os professores no contexto de um curso de educação superior em moda?

0 objeto de estudo foi um curso de graduação em moda de uma universidade do estado do Paraná. 0 curso está inserido no conhecido corredor da moda do Paraná, onde existe um arranjo produtivo local na área de confecção.

0 objetivo geral da pesquisa foi investigar como ocorre o compartilhamento do conhecimento nas intervenções e práticas de ensino aplicadas na disciplina de modelagem do vestuário entre os professores do curso analisado. 0 tratamento da problemática proposta pela pesquisa exigiu amplo apoio na literatura com o intuito de se realizar uma revisão bibliográfica que pudesse contribuir, de alguma maneira, para a atualização das discussões sobre o tema.

0 curso de graduação em moda relaciona o vestuário e o processo de construção da roupa, o que exige habilidades específicas no setor de desenvolvimento de produto, modelagem e confecção (MARIANO, 2011). No que se refere ao processo de construção do vestuário, a estética é fundamental, mas a vestibilidade da roupa também. A vestibilidade da roupa está diretamente ligada à modelagem do vestuário. 0 profissional responsável pela modelagem deve ser capaz de interpretar os diferentes desenhos de roupas criados pelos estilistas, transformando-os em moldes, que unidos vão formar a roupa imaginada ao vestir o corpo almejado (MARIANO, 2011).

Nesse contexto, a disciplina de modelagem adquire importância específica nos cursos de graduação em produção do vestuário e design de moda, pois uma das suas finalidades é formar novos profissionais responsáveis por essa função (MENEZES; SPAINE, 2010). Para trabalhar a disciplina de modelagem de forma a ampliar os referenciais de conhecimento, assim como promover o seu compartilhamento, pode ser importante que haja o compartilhamento do conhecimento entre os professores que ministram a disciplina.

Na temática compartilhamento do conhecimento, buscou-se expor o conceito deste assunto. Em síntese, ao compreender como ocorre esse compartilhamento entre os professores da disciplina de modelagem, esperou-se identificar o processo de construção da disciplina dentro do curso de moda de uma universidade do estado do Paraná. 


\section{Compartilhamento do conhecimento}

Definir o que é o conhecimento e mesmo a gestão do conhecimento envolve diferentes correntes teóricas, cada qual com suas particularidades. Ocorre o mesmo quando se fala em compartilhamento do conhecimento. Contudo, antes de apresentar esse conceito é preciso entender que, nas interações sociais em que ocorre o compartilhamento do conhecimento, há um processo de comunicação que o permeia e que nele interfere simultaneamente.

Os pesquisadores não apresentam uma concordância de ideias sobre o que é o compartilhamento de conhecimento e como ele acontece entre os indivíduos, sendo que esse impasse gerou a diversidade de denominações para este fenômeno como, por exemplo, transferência, repasse de conhecimento (TONET; PAZ, 2006). Apesar do debate conceitual sobre 0 tema, grande parte dos pesquisadores afirma que o compartilhamento do conhecimento existe nos quatro processos de interação social da gestão do conhecimento: criação, retenção, transferência e aplicação. Assim, seu domínio ganha importância para as organizações, por ser um desafio para estas a administração deste fenômeno social (VASCONCELOS et al., 2013).

Desta forma, o compartilhamento do conhecimento torna-se requisito preliminar para aquelas instituições que desejam manter e disseminar, dentro do seu grupo de colaboradores, aquele conhecimento tido como base da organização (PROBST; RAUB; ROMHARDT, 2002). Bartol e Srivastava (2002), citados por Tonet e Paz (2006, p. 77), definem

[...] compartilhamento do conhecimento como sendo o compartilhamento de informações, ideias, sugestões e experiências organizacionalmente relevantes, do indivíduo com outros, e afirmam que o compartilhamento do conhecimento é uma componente chave dos sistemas de gestão do conhecimento.

Em outras palavras, para Bartol e Srivastava o compartilhamento do conhecimento envolve a troca das mais variadas experiências e ideias entre individuos; contudo, há que se destacar que nem sempre a troca ocorre. Compartilhar significa expor as ideias e, ao mesmo tempo, saber ouvir e não simplesmente impor um determinado conhecimento ou mesmo apresentá-lo de forma pouco acessivel a todos.

Em que pese a importância dada ao compartilhamento de informações, constata-se que, muitas vezes, a transmissão do conhecimento encontra certos bloqueios como, por exemplo, o fato de serem utilizadas palavras técnicas e terminologias modernas que não se enquadram no perfil do receptor, gerando uma falta de compreensão das informações que visam ser repassadas. 
Essa inadequação entre o conhecimento retido e o conhecimento transmitido gera uma barreira na difusão cognitiva, acarretando uma problemática a ser resolvida pela gestão do conhecimento organizacional, que tem como principal foco a captura dos conhecimentos tácitos dos trabalhadores para torná-los explícitos a fim de que possam ser usados por outros colaboradores ou por parceiros empresariais da organização (OLIVEIRA; OLIVEIRA; LIMA, 2016).

Diante desta situação, surgem ideias sobre como se processar de forma mais eficiente o compartilhamento do conhecimento nas organizações, destacando-se duas maneiras de realizar isto: por meio da informação (o compartilhamento ocorre de forma indireta por meio de palestras, apresentações audiovisuais, manuais e livros) ou tradição (o conhecimento passa a ser compartilhado de forma direta, de pessoa para pessoa), sendo que ambas podem ocorrer de modo formal ou informal (ANGELONI; MULBERT, 2008; STEIL, 2007).

Para Takeuchi e Nonaka (1997), o compartilhamento do conhecimento ocorre nos quatro modos de conversão da espiral do conhecimento: socialização, externalização, combinação e internalização. Na socialização a conversão do conhecimento acontece de indivíduo para indivíduo, de tácito para tácito. Portanto, o diálogo e a observação entre os indivíduos se fazem necessários para que ocorra o compartilhamento do conhecimento. Na externalização a conversão de conhecimento acontece de indivíduo para grupo, de tácito para explícito; assim, há que ocorrer o desejo do individuo de compartilhar o seu conhecimento implícito para o grupo.

Na combinação a conversão do conhecimento acontece de individuo para grupo, de explícito para explícito. Logo, o emissor tem que ter domínio do conteúdo para conseguir compartilhar o conhecimento para seus receptores. Na internalização a conversão do conhecimento ocorre da organização para o indivíduo, de explícito para tácito; consequentemente, a empresa tem que encontrar formas adequadas e apraziveis para compartilhar esse conhecimento com seu colaborador (TAKEUCHI; NONAKA, 2008). Takeuchi e Nonaka (1997) afirmam que o conhecimento tácito é compartilhado por meio do vínculo diário entre os indivíduos e que precisa existir a confiança reciproca para que o fenômeno se concretize.

0 compartilhamento do conhecimento exige, deste modo, disposição das organizações para aprender a partir de novas ideias expostas pela equipe. Portanto, as organizações têm que estar abertas a mudanças para que ocorra a inovação constantemente. De acordo com Oliveira, Oliveira e Lima (2016, p. 26), "a base fundamental do modelo de gestão do conhecimento organizacional está centrada no compartiIhamento do conhecimento [...]". Ou seja, para que existam a gestão do 
conhecimento e a aprendizagem coletiva, faz-se necessário que todos estejam dispostos a compartilhar seus saberes.

Ao pensar o processo de compartilhamento como base para o processo de aprendizagem, Rabelo et al. (2012) destacam o fato de que esse processo promove o desenvolvimento, não apenas do indivíduo, mas de grupos e mesmo de instituições a partir do momento em que são capazes de criar conhecimento e não apenas reproduzi-lo. A gestão do conhecimento organizacional deve ater-se a produzir e não somente a reproduzir o conhecimento.

0 compartilhamento do conhecimento é uma das etapas da gestão do conhecimento e ele ocorre como um processo social de aprendizagem; assim sendo, a interação das pessoas é de suma importância. Portanto, nas organizações de ensino pode ocorrer a captura, retenção, compartiIhamento e aplicação do conhecimento, o que é possivel de ser avaliado (MARIANO, 2011). Esse processo se dá em todos os cursos de graduação, pós-graduação ou mesmo em projetos de extensão. 0 foco desta pesquisa se volta para os cursos de moda, responsáveis pela formação dos profissionais atuantes no setor têxtil.

Os cursos de moda, por serem considerados novos na academia, abrangem ainda poucos estudos a respeito de metodologias de ensino direcionadas às disciplinas teórico-práticas. A modelagem do vestuário, como uma dessas disciplinas, alia a criação e a concretização da peça. 0 ensino de modelagem do vestuário, compreendido como processo de concretização de uma ideia, é permeado por conceitos de idealização e construção de uma peça de vestuário em uma relação harmônica, com um produto final coerente (COSTA, 2016).

De acordo com Costa (2016), o desenvolvimento de uma peça de roupa é algo complexo, exigindo conhecimentos voltados ao corpo e sobre como transformar o tecido em moldes para então confeccionar uma peça de roupa. 0 profissional responsável pela construção dos moldes - partes que unidas formam a roupa - é o modelista, e sua profissionalização é fundamental para boa execução do seu trabalho.

Mais do que apenas conhecer a teoria, a disciplina exige a aplicação dessa teoria e a capacidade de interpretar as medidas do corpo assim como a capacidade de transpor essas medidas e transformá-las em moldes que darão forma à roupa. Essas formas ainda estão em processo de criação por meio das ideias dos estilistas. Assim, pensar o compartilhamento do conhecimento para o ensino da disciplina de modelagem do vestuário demanda refletir sobre quais as formas mais adequadas de compartilhamento, que não somente permitam a retenção de informações, mas que promovam a criação do conhecimento. 


\section{Metodologia}

0 objetivo geral definido para esta pesquisa foi o de investigar como ocorre o compartilhamento do conhecimento nas intervenções e práticas de ensino aplicadas na disciplina modelagem do vestuário entre os professores no decorrer de um curso de educação superior em moda.

Logo, tendo o objetivo geral como critério de classificação, esta pesquisa foi de natureza qualitativa de cunho exploratório e apresentou estudo de caso envolvendo uma única unidade de análise (YIN, 2005).

A coleta de dados foi realizada por meio de entrevistas semiestruturadas, além de consulta a documentos institucionais, e os resultados obtidos foram analisados na proposta de Bardin (2011) sobre análise de conteúdo.

A unidade de pesquisa foi um curso de moda de uma universidade estadual do Paraná, cuja identificação nesta pesquisa é a denominação "universidade A", a fim de ser mantido seu anonimato. Foram entrevistadas cinco professoras responsáveis pela disciplina de modelagem do vestuário. Para manter os critérios exigidos pelo comitê de ética que aprovou a realização dessa pesquisa, a identificação das cinco participantes se fez por letras do alfabeto grego, também a fim de manter seu anonimato. Elas foram designadas como: Alfa, Beta, Delta, Gama e Zeta. As entrevistas realizadas para este estudo tiveram, em média, a duração de quarenta minutos com cada professora. As professoras foram avisadas antecipadamente que a entrevista seria gravada e transcrita para posterior análise de conteúdo e publicação, e deram seu consentimento. As entrevistas aconteceram nos dias 24 e 25 de maio de 2017.

A entrevista foi dividida em três etapas distintas. A primeira etapa correspondeu ao processo de compreensão do contexto referente ao curso, 0 primeiro de graduação em moda em uma universidade estadual do Paraná; buscou-se conhecer sua estrutura e a sua organização, bem como sua grade curricular. A segunda etapa referiu-se ao conhecimento da estrutura da disciplina de modelagem do vestuário, como é ministrada, quais são os conteúdos e atividades realizadas em sala. Por fim, buscou-se compreender como ocorre o processo de compartilhamento do conhecimento referente a esta disciplina entre as professoras. Destaca-se que, ao ter conhecimento de seu funcionamento, os pesquisadores tiveram bases necessárias para avaliar, de antemão, algumas práticas de gestão do conhecimento e aprofundar a entrevista com vistas a responder o problema em questão.

As entrevistas gravadas geraram arquivos de áudio (ALFA, 2017; BETA, 2017; DELTA, 2017; GAMA, 2017; ZETA, 2017) que foram transcritos. Foi realizada leitura dos relatos transcritos e em seguida passou-se a estruturá-los em um primeiro momento por temas agrupados. Esses temas foram abordados no roteiro de entrevista e expostos livremente pelas professoras. 
A seguir os temas foram distribuídos para os três objetivos específicos conforme se apresentava compativel com cada um.

Para o primeiro objetivo específico - "investigar se há registros ou discussões voltadas à organização, estruturação e desenvolvimento da disciplina de modelagem ao longo do tempo de um curso de moda" - foram categorizados dois temas: evolução do curso e registros de evolução do curso.

Para o segundo objetivo específico - "investigar qual método de ensino da modelagem do vestuário é abordado pelos professores" - não houve a necessidade de categorizar por tema. Para o terceiro objetivo - "compreender a percepção das professoras quanto ao compartilhamento do conhecimento" - foram categorizados três temas: importância do compartiIhamento do conhecimento, importância do trabalho em equipe e rotinas para discutir práticas de ensino. Foram apontados indicadores favoráveis ao compartilhamento do conhecimento entre as professoras.

\section{0 estudo de caso}

No Brasil, durante o período compreendido entre os anos de $1995 \mathrm{e}$ 2003, o estado do Paraná foi o que mais cresceu no que se refere ao número de estabelecimentos e empregos no setor de vestuário. 0 estado foi classificado como o segundo maior polo industrial de confecção do Brasil em 2003, produzindo 216 milhões de peças por ano (OLIVEIRA; CÂMARA; BAPTISTA, 2007).

0 curso de moda em nível superior e gratuito no Paraná foi implantado na universidade A em 24 de fevereiro de 1997, sendo reconhecido em 20 de novembro de 2001, conferindo ao discente concluinte o grau de bacharel em Estilismo em Moda. 0 mesmo curso teve sua nomenclatura alterada em 18 de agosto de 2004 para Design de Moda. Conforme pesquisa realizada com professoras deste curso, a entrevistada Alfa afirma que " 0 curso de moda daqui surgiu pela necessidade de mercado" (ALFA, 2017, informação verbal).

A universidade A faz parte do eixo norte e noroeste do estado, conhecido como corredor da moda. Fazem parte do corredor da moda as cidades de Maringá, Cianorte, Apucarana e Londrina (CARREIRA, 2001). Ele possui um Arranjo Produtivo Local (APL) na área de confecção, que possibilita ao empreendedor estar inserido em um território onde a dimensão construtiva é economicamente viável.

Um Arranjo Produtivo Local' ${ }^{1}$ é caracterizado pela existência da reunião de um número significativo de empresas que atuam em torno de uma atividade principal. Para isso, é preciso considerar a dinâmica do território em que essas empresas estão inseridas, tendo em vista o número de postos de 
trabalho, faturamento, mercado, potencial de crescimento, diversificação, entre outros aspectos. Além disso, é fundamental que o espaço geográfico possua sinais de identidades diversas: sociais, culturais, econômicos, politicos, ambientais ou históricos (FERREIRA, 2013).

Nesse contexto, cabe destacar a importância do curso de moda da universidade A para a realidade econômica local, uma vez que abre a oportunidade de capacitação de profissionais para atuarem em um mercado com grande demanda na região.

Este curso de moda, implantado em 1997, tem como objetivo:

Formar designers de moda, integrados à realidade contemporânea, capazes de projetar objetos e/ou sistemas de objetos de uso por meio do enfoque interdisciplinar, considerando as características dos usuários e de seu contexto socioeconômico e cultural, bem como potencialidades e limitações econômicas e tecnológicas das unidades produtivas (PROGRAD, 2016, p. 20).

Nota-se que o aluno formado pela universidade A deve apresentar habilidades para ver um conjunto e, além disso, ser capaz de diagnosticar uma situação ampla e resolver qualquer problema de design. Em entrevista realizada com as professoras do curso, a entrevistada Beta relata:

0 mais importante é que o designer de moda formado aqui na universidade A tenha uma visão sistêmica. Por exemplo, se falar em vestuário, ele não vai pensar só na modelagem, ele vai pensar na modelagem, no corte, na costura, em quem vai usar, onde ele vai usar, que tecido ele usa, se esse tecido é sustentável (BETA, 2017, informação verbal).

0 que se percebeu é que o designer de moda formado particularmente nessa universidade é instruído a observar o conjunto como um todo e não isolar partes do sistema. No caso de um produto do vestuário, para que este se materialize, o designer deve estar atento ao que é necessário à sua construção: público-alvo, ocasião de uso, sustentabilidade do produto, tecido, modelagem, aviamentos, costura entre outros.

O desenvolvimento do curso e a disciplina de modelagem

\section{Evolução do curso}

Buscando investigar como é organizada a disciplina de modelagem do vestuário dentro de um curso superior em moda, tem-se nesta seção a apresentação do desenvolvimento do curso e o modo como são pensadas e narradas as práticas de ensino aplicadas na disciplina de modelagem do vestuário entre as professoras. 
Cabe destacar que, ao questionar as entrevistadas sobre a estrutura do curso e seu funcionamento, a fala da entrevistada Zeta chamou a atenção: "não há somente o pensar na disciplina de modelagem do vestuário. A gente tem um projeto super inovador, muito bacana, fruto de anos de estudo" (ZETA, 2017, informação verbal).

Para a entrevistada, todas as disciplinas são pensadas de forma integrada, não somente a de modelagem do vestuário. Isso se deve ao fato de que o projeto de ensino do curso é inovador e veio de um processo de estudo. Compreende-se, nessa resposta, que não há referência apenas à disciplina de modelagem do vestuário, mas ao curso como um todo, o que pode caracterizar um pensamento sistêmico, conexão de todo sistema que compõe o curso (SENGE, 2016).

0 curso iniciou com a nomenclatura de estilismo, com disciplinas estanques em cada série, evoluindo gradativamente dentro de um contexto pedagógico normal, tradicional. Eu não vou saber precisar o ano, mas a equipe e o corpo docente escreveram um projeto de ensino para estudar a reformulação do curso (ZETA, 2017, informação verbal).

Nesse fragmento da fala da entrevistada, observam-se dois aspectos importantes: que o curso evoluiu gradativamente em um contexto pedagógico tradicional (disciplinas trabalhadas de maneira isolada) e que, posteriormente, fora feito um estudo para reformulação dele. 0 processo de reformulação do curso não partiu de um único responsável, mas sim do corpo docente como um todo, o que indica uma cooperação entre os professores e que pode caracterizar um trabalho em equipe. Pode-se dizer, então, que a equipe se uniu para compartilhar ideias sobre o plano pedagógico.

Compartilhar ideias é uma das práticas da gestão do conhecimento, conforme afirmam Bartol e Srivastava (2002). Para os autores, "compartiIhamento do conhecimento é o compartilhamento de informações, ideias, sugestões e experiências organizacionalmente relevantes do individuo, com outros" (BARTOL; SRIVASTAVA, 2002 citados por TONET; PAZ, 2006, p. 77). 0 compartilhamento do conhecimento é um item essencial nos processos da gestão do conhecimento, o que exige dos professores uma disposição para discutir ideias e chegar em um consenso.

A professora Zeta apresentou, em sua narrativa, como se deu o processo de mudança do plano pedagógico:

Queriamos uma configuração que realmente acoplasse a moda no contexto do design, mais do que isso, queriamos um projeto inovador, interdisciplinar e que essa interdisciplinaridade de fato 


\begin{abstract}
ocorresse. Então, passamos quatro anos estudando teorias educacionais, teorias de ensino e aprendizagem, metodologias contemporâneas com assessoria de doutores em educação e com assessoria de outros profissionais da área e de áreas multidisciplinares. Foram quatro anos de estudos. 0 projeto foi bem amplo, o que culminou na reformulação curricular do estilismo e moda para design de moda (ZETA, 2017, informação verbal).
\end{abstract}

No ano de 2004, a área de moda passou a ser avaliada pelo MEC como um conhecimento que compõe a grade curricular da área do design e muitos cursos tiveram de reelaborar seus planos pedagógicos para vincular-se ao contexto do design (AGUIAR, 2015). A reestruturação dos cursos deveria ser feita com base nas Diretrizes Curriculares Nacionais do Curso de Graduação em Design, consolidadas pela Resolução CNE/CES nº 5, de 8 de março de 2004.

0 que se percebe na fala da entrevistada Zeta é que os professores da universidade pesquisada tinham a preocupação em conectar a moda realmente ao contexto do design. Eles tinham uma visão compartilhada quanto ao interesse por inovar o curso e que, de fato, essa inovação pudesse ocorrer como uma prática interdisciplinar. Para Senge (2016, p. 300), "[n]o nivel mais simples, uma visão compartilhada é a resposta à pergunta: 0 que queremos criar?" Assim, foi possivel interpretar que este grupo docente tinha uma visão compartilhada de promover a ação de inovação no curso com base em práticas interdisciplinares, o que permitiu que todos se organizassem na promoção de um interesse comum.

Nota-se que, para atingir o objetivo, alterar o plano pedagógico e construir uma visão compartilhada entre a equipe de professores, houve um processo de mudança e que não foi imediato. De acordo com Davenport (1998), os professores identificaram, interpretaram, filtraram, categorizaram e integraram as informações para, assim, formar o conhecimento organizacional e criar melhores práticas de trabalho que pudessem auxiliar na melhoria e mudança do curso.

\title{
Método de ensino de modelagem do vestuário
}

Existem vários métodos que ensinam o traçado dos diagramas. Os métodos podem ser encontrados em livros didáticos como: método Gil Brandão, método Denner, método Vogue, método industrial brasileiro, entre outros, sendo que cada método apresenta técnicas diferenciadas, o que depende de cada autor. Quando questionadas sobre o uso de métodos de ensino de modelagem do vestuário, as professoras foram unânimes em responder que mesclam os métodos. A entrevistada Gama relata: 
pois esperamos que o aluno entenda que não existe um método certo, que existem formas de pensar e o que ele tem que entender é a configuração disso num corpo enquanto roupa, mas não é algo "engessadinho" que você tem que seguir como receita (GAMA, 2017, informação verbal).

Percebe-se, na fala da entrevistada, que existe uma liberdade para as professoras escolherem, entre os existentes, qual é o método de ensino de modelagem do vestuário com o qual mais se identificam para trabalhar e que, muitas vezes, elas ainda mesclam os métodos, conforme se percebe na fala da entrevistada Beta:

Mescla-se muito, porque assim, cada pessoa trabalha com as suas referências, mas às vezes, de acordo com cada turma você tem que mudar o teu panorama de aula e conforme a turma vai respondendo você complementa. $E_{1}$ dessa forma, mescla-se muito (BETA, 2017, informação verbal).

$\mathrm{Na}$ fala da entrevistada, há certa preocupação por parte das professoras com o ensino e aprendizagem dos alunos, sendo que, muitas vezes, é necessário recorrer a outros métodos de ensino de modelagem do vestuário para que haja melhor entendimento do conteúdo por parte do aluno, permitindo-o conseguir analisá-lo de maneira crítica. A professora Delta afirma: "eu entendo que ter essa democracia, essa coisa de poder trabalhar com diferentes métodos, é algo que enriquece" (DELTA, 2017, informação verbal).

Existem muitos métodos que ensinam como preparar o molde da roupa, e cada um apresenta uma técnica específica (VILLAÇA; CASTILHO, 2006). 0 que as professoras pesquisadas deixam em evidência é a importância de se trabalhar com vários métodos, para que o aluno não se prenda apenas a uma técnica de ensino, mas seja capaz de questioná-las e, com isso, ampliar sua visão quanto ao conhecimento da modelagem do vestuário.

A modelagem do vestuário não trata de reproduzir formas, mas de interpretá-las, criar soluções para construir uma peça de roupa. Dessa maneira, é preciso buscar informações em várias fontes, em diferentes métodos de ensino de modelagem do vestuário, a fim de criar o próprio conhecimento, o que pode tornar possivel uma inovação na técnica.

Quando as entrevistadas foram questionadas se há registros ou discussões voltados à organização, estruturação e desenvolvimento da disciplina de modelagem ao longo do tempo, no curso de moda, vale ressaltar a narrativa da professora Beta: "tem de todas as disciplinas, pois estamos sempre fazendo reuniões para falar do curso, para falar do aluno, enfim, para falar de várias coisas" (BETA, 2017, informação verbal). 
Nota-se que não há registro de mudança somente das disciplinas de modelagem do vestuário; pelo contrário, de todas as disciplinas e dos mais variados assuntos sobre o curso e sobre alunos.

A entrevistada Gama explica, em sua narrativa, como funciona a integração das disciplinas:

A gente trabalha por projetos. Então, hoje, a minha disciplina tem que estar junto com a sua. Eu sou de modelagem, você é da costura. E aí estamos finalizando uma atividade onde o aluno desenvolveu um molde na aula de modelagem e, agora, ele vai montar essa peça para entender se o molde deu certo ou deu errado. Então o professor de costura tem que estar junto, porque é ele que vai dar o aporte da costura, mas o professor de modelagem participa para ajudar no pensamento da verificação. Então temos essa flexibilidade, nosso horário não é fixo (GAMA, 2017, informação verbal).

A entrevistada destaca o valor da presença de professores de outras disciplinas em sala quando, por exemplo, faz-se necessária a presença do professor de costura durante a aula de modelagem do vestuário auxiliando os alunos na montagem da peça. A modelagem do vestuário é composta por partes de moldes que, quando cortados em tecidos e unidos pela costura, dão forma à roupa pensada pelo design (OSÓRIO, 2007). 0 professor de costura sabe orientar o aluno quanto à sequência operacional da peça para se conseguir o melhor acabamento do produto, bem como qual maquinário é adequado para tal tipo de tecido e acabamento. Para cada tipo de acabamento é um valor de margem de costura, o que interfere no produto final caso não seja pensado durante o desenvolvimento da modelagem do vestuário (ARAUJO, 1996).

Observa-se que, para desenvolver um produto de moda, precisa-se de informações de diversas áreas do conhecimento. Alário (2007) afirma que a formação do designer de moda exige conhecimentos teórico-práticos provenientes de diversas disciplinas como: desenho manual e gráfico, têxtil, modelagem, laboratório de confecção, design, história da moda e outros, 0 que depende da grade do curso. E para a realização da modelagem do vestuário, foco deste trabalho de pesquisa, o aluno deve apresentar conhecimentos básicos de geometria, antropometria, anatomia do corpo humano e ergonomia. E, se as disciplinas trabalharem integradas, o entendimento do aluno pode ser ampliado.

Os professores têm consciência de que essa interdisciplinaridade só funciona porque existe diálogo entre a equipe de trabalho. E entendem que a teoria e a prática, sendo compartilhadas por eles, interfere na aprendizagem do aluno que consegue entender com mais facilidade as conexões entre as disciplinas. 


\section{Compartilhamento do conhecimento entre professoras}

Buscando compreender a percepção das professoras quanto ao compartilhamento do conhecimento notou-se, por meio das narrativas, que elas se aproximam pelas suas descrições. Para elas, o compartilhamento do conhecimento funciona como meio de promover a integração e inovação. Acrescentam ainda que se trata de um recurso para incentivar a percepção do processo de ensino e aprendizagem como promoção da construção do conhecimento individual, quer seja do professor, quer seja do aluno.

Deste modo, tem-se que compartilhar conhecimento é uma forma de mediar o processo de formação dos alunos, uma vez que contribui para a construção individual deles. Percebe-se também que compartilhar conhecimento promove a aprendizagem coletiva dos professores e, com isso, vai-se construindo o conhecimento organizacional que, nesse caso, mostra-se contínuo. Davenport (1998, p. 78) afirma que "o conhecimento das organizações é um artefato social, construído das experiências coletivas de sua força de trabalho, dos talentos que ela recompensa e das histórias compartilhadas dos triunfos e erros da empresa".

0 compartilhamento do conhecimento é quesito preliminar para a instituição de ensino que deseja manter e disseminar, dentro do seu grupo de professores, o conhecimento tido como base da organização. Ele tem participação em todo o processo de gestão do conhecimento e ocorre como um recurso social de aprendizagem; portanto, o diálogo entre os professores é primordial (PROBST; RAUB; ROMHARDT; 2002).

Para melhor análise do conteúdo foram agrupados e analisados os temas citados no roteiro da entrevista e expostos livremente nos relatos das professoras resultando nas seguintes categorias temáticas: importância do compartilhamento do conhecimento, importância do trabalho em equipe $e$ rotinas para discutir práticas de ensino.

\section{Importância do compartilhamento do conhecimento}

Buscando compreender a percepção das professoras quanto ao compartilhamento do conhecimento no decorrer da evolução de um curso de moda, o primeiro questionamento foi sobre a importância do compartilhamento do conhecimento para elas. Cabe destacar o relato da entrevistada Beta:

0 compartilhamento do conhecimento é essencial, com certeza! Isso é óbvio, sem dúvidas! Não é isso que a gente faz? Afinal, a gente pesquisa para isso. Pesquisamos porque o objetivo é esse, não é um fazer a sua pesquisa e deixar lá engavetada. É para realmente disseminarmos e trocarmos conhecimento (BETA, 2017, informação verbal). 
Um aspecto que influencia a gestão do conhecimento é a predisposição dos indivíduos em compartilhar ou reter conhecimentos. Takeuchi e Nonaka (2008) apresentam em seus estudos o seguinte: é por meio da confiança e do entendimento entre os colaboradores que pode surgir a disposição destes para o compartilhamento do conhecimento individual.

0 que se percebe no relato de Beta é que a entrevistada reconhece a importância de não reter conhecimento para si, apresentando uma disposição para compartilhar suas pesquisas. Além disso, Beta reconheceu os benefícios do compartilhamento do conhecimento e os considerou relevantes para disseminar novas práticas. Outro ponto a ser ressaltado é a palavra troca, pois o compartilhamento do conhecimento não aborda apenas a concepção de armazenar, mas, também, de debater informações, ideias, sugestões e de discutir o que já foi feito, bem como as possibilidades de aprimoramento. Conforme descrevem Tonet e Paz (2006, p. 77), "compartiIhamento do conhecimento é o compartilhamento de informações, ideias, sugestões e experiências [...]."

A entrevistada Gama relata: "0 tempo todo compartilhamos conhecimento. Mesmo às vezes até informalmente. Nas conversas de corredor mesmo, não só em sala de aula ou reuniões" (GAMA, 2017, informação verbal). 0 relato da entrevistada Beta acrescenta o seguinte:

0 objetivo é esse, discutir só para melhorar o curso, melhorar o entendimento do aluno, melhorar o aprendizado, são essas coisas. Conversamos nos corredores, em sala de aula, nas reuniões de colegiado. Então é muito flexível isso, depende muito do que a gente quer, da necessidade (BETA, 2017, informação verbal).

Observa-se, na fala da entrevistada, que o diálogo dos professores ocorre nos mais diversos lugares, de maneira formal e informal, e que compartilhar conhecimento faz parte do cotidiano deles.

Nota-se que o compartilhamento do conhecimento é relevante, pois é uma forma de repassar o conhecimento adquirido em experiências pessoais, conforme apontam Tonet e Paz (2006) e a fala das professoras participantes desta pesquisa. As experiências pessoais, quando expostas entre as professoras, podem gerar ideias inovadoras e proporcionar o crescimento profissional de todos e da instituição, a qual tem a opção de arquivar os conhecimentos produzidos como informações que poderão ser reutilizadas por futuros professores, caracterizando assim a gestão do conhecimento.

A entrevistada Zeta continua a narrativa justificando o seguinte:

Isso é colocado até no teste seletivo: você tem perfil para trabalhar em equipe? 0 curso ele é configurado dessa forma, serve para você? Na arguição é colocado para o candidato que a cultura de trabalhar 
no curso tem essa configuração: demanda trabalho em equipe, demanda uma planilha docente que excede a carga horária que ganha. Isso é cultural. Entendemos isso como investimento, investimento na carreira, investimento no currículo [...]. A pessoa que entra aqui tem que ter esse perfil, porque se ela não tiver, até entra, mas não fica, entende? (ZETA, 2017, informação verbal).

Observa-se que trabalhar em equipe é primordial para as professoras, faz parte da cultura do curso e, além disso, há situações em que o horário normal de trabalho é excedido voluntariamente, sem remuneração. Faz parte dessa cultura organizacional, pois os docentes entendem isso como um investimento pessoal.

A entrevistada Beta acrescenta, em um trecho da sua fala, que

\begin{abstract}
Têm professores - se bem que na nossa área é mais dificil - que querem dar a aulinha lá fechado na sala, não querem ninguém, não querem mudar nada no método. Não serve para nós. Para o nosso pensamento não serve, não adianta, não aprovamos. Não adianta você só ter o conhecimento da disciplina que vai lecionar, tem que ter e minimamente se enquadrar na nossa cultura do curso. Então é fácil de você ver se a pessoa é muito rígida, dura, se ela não tem muito jogo de cintura, é assim (BETA, 2017, informação verbal).
\end{abstract}

Nota-se que o professor almejado pela universidade A para trabalhar no curso de moda, em específico, precisa apresentar domínio pessoal, ou seja, deve ser capaz de aceitar mudança na forma de pensar e trabalhar a fim de se enquadrar na dinâmica das atividades em equipe, não bastando ter apenas o conhecimento da matéria lecionada (SENGE, 2005).

Assim sendo, o trabalho em equipe exige dos professores um pensar em conjunto (pensamento sistêmico), muito diálogo e a capacidade de deixar de lado ideias preconcebidas em seus modelos mentais, possibilitando a aprendizagem coletiva da organização (SENGE, 2016). Pode-se concluir que a gestão do conhecimento organizacional só é possivel se ocorre mudança comportamental e cultural na organização.

\title{
Importância do trabalho em equipe
}

Buscando compreender a percepção das professoras quanto ao compartilhamento do conhecimento, elas foram questionadas sobre a importância do trabalho em equipe, o qual é considerado por Peter Senge (2016) um dos meios favoráveis para o compartilhamento do conhecimento. 0 trabalho em equipe é caracterizado como um processo que apresenta qualidades coletivas como colaboração, flexibilidade, apoio sincero, confiança no próximo, consciência das pessoas de que o seu sucesso depende de outras pessoas, compromisso com um único objetivo (CARDOSO, 1998). 
Com o intuito de mostrar a importância do trabalho em equipe para o compartilhamento do conhecimento, apresenta-se o relato da entrevistada Beta:

É essencial porque, às vezes, estamos muito voltadas para nossas pesquisas. Eu tenho meu doutorado, outra pessoa tem o doutorado dela. A gente fica muito fechada nas nossas pesquisas e, para você, algumas coisas são meio óbvias. Quando conversamos com o outro e entendemos o que o outro está fazendo, abrimos muitos horizontes. Isso é muito importante! $E$, às vezes, principalmente pela troca, você vê isso assim, mas eu não vejo, mas como é que eu posso começar a enxergar um pouco do seu, e você do meu? A pessoa enriquece muito (BETA, 2017, informação verbal).

Nessa fala da entrevistada Beta, percebe-se a importância do trabalho em equipe para se conversar, discutir e trocar experiências. E que o diálogo possibilita compartilhar conhecimento e discutir, a fim de que, nessa interação, possa ocorrer a reflexão e o entendimento de diversas linhas de pensamento pelos professores. Essa prática pode levá-los a rever seus modelos mentais e ajustá-los aos conhecimentos compartilhados, momento em que todos ganham nessa interação.

A entrevistada Zeta acrescenta que:

Trabalhar em equipe é fundamental, pois tudo o que se constrói em equipe você trabalha com múltiplos olhares e você sai daquele olhar linear quadradinho, que só você enxerga, porque muitas vezes, dentro de um mesmo conteúdo, dentro de uma mesma área, quantos olhares não pode ter? [...] então, uma mesma coisa pensada sobre diversos olhares é de uma riqueza indiscutivel (ZETA, 2017, informação verbal).

$\mathrm{Na}$ fala da entrevistada, fica evidente o quanto é importante trabalhar em equipe, e que cada professor tem uma linha de pensamento. Essas diferentes linhas se ampliam quando as visões são compartilhadas, propiciando um aprimoramento de qualquer que seja o objeto de estudo.

A entrevistada Beta acrescenta mais:

Temos uma equipe pequena, uma equipe que se entende muito bem, se entrosa muito bem [...]. Não existe trabalho sem diálogo, ainda mais nesse modelo nosso que é tudo muito flexivel, é muito sistêmico, e as pessoas precisam - porque isso também não é uma coisa fácil. Por que que muita gente não trabalha assim? Porque não é fácil o relacionamento entre as pessoas, não é muito simples. Graças a Deus a gente tem uma equipe que se entende muito bem (BETA, 2017, informação verbal). 
Observa-se, na fala da entrevistada, que trabalhar em equipe não é algo fácil e que esse modelo exige muitas conversas, discussões, trocas de informações e que ter bom relacionamento é primordial para ocorrer o entendimento dos assuntos e o trabalho sistêmico fluir. E que, nesse caso, a equipe se entende muito bem, por isso o pensamento sistêmico está dando certo no curso. A professora Delta soma a esse contexto: "a gente tem um relacionamento muito tranquilo, muito bom" (DELTA, 2017, informação verbal).

Shinoda (2012) afirma que são fatores facilitadores para o compartiIhamento do conhecimento aspectos como: confiança entre as pessoas, abertura para o diálogo, respeito e transparência.

\section{Rotinas para discutir práticas de ensino}

Buscando compreender a percepção quanto ao compartilhamento do conhecimento, o terceiro questionamento para as professoras foi se existem rotinas para discutir práticas de ensino.

Quando questionada sobre os encontros para discutir práticas de ensino de modelagem do vestuário, a entrevistada Alfa relatou: "Aqui nós não separamos: esse é de modelagem, esse é de criação. São todos juntos, porque todos fazem parte de tudo, não tem essa divisão" (ALFA, 2017, informação verbal). Nessa fala da entrevistada, percebe-se um pensamento sistêmico. Vasconcelos (2002) afirma que, enquanto na forma tradicional o mundo é visto de maneira fragmentada, no pensamento sistêmico o mundo é visto em sistemas inseparáveis.

A entrevistada Beta afirma, em seu relato, que "todos os professores se encontram sempre. Não vou te dizer que é somente o de modelagem não, os nossos encontros são entre todos. Às vezes eu nem vejo que estou discutindo com alguém da modelagem, a gente discute no geral" (BETA, 2017, informação verbal).

A entrevistada Zeta acrescenta que "quando se estava implementando os projetos aconteciam reuniões semanais, no mínimo uma tarde por semana e eram em torno de discutir os processos metodológicos de todas as disciplinas" (ZETA, 2017, informação verbal).

Nota-se, na fala das entrevistadas, que frequentemente ocorrem encontros entre os professores, que não são somente de modelagem do vestuário, e que as discussões são de âmbito geral dos projetos que envolvem o curso de moda. 0 que se percebe, nesse ponto, é que os professores trabalham em equipe. Senge (2016) afirma que o trabalho em equipe se inicia pelo diálogo e discussão e que os membros de equipe devem apresentar capacidade de deixar de lado ideias preconcebidas em seus modelos mentais para participarem de um pensamento sistêmico. Os modelos mentais 
são imagens que influenciam nossa forma de ver o mundo e de agir, os quais devem ser repensados pelos professores, para que, dessa forma, seus atos e decisões na instituição não sejam influenciados por visões de mundo distorcidas da realidade (SENGE, 2016).

A professora Beta acrescenta, em sua narrativa, um exemplo das discussões:

\begin{abstract}
Se em algum momento percebemos que alguma coisa não vai bem, como por exemplo, o mundo aí está mudando, por que ainda estamos fazendo isso? Então discutimos e a gente vai tentando mudar, na medida do possível. Se a mudança é radical e exige uma mudança ou de disciplina, ou de projeto pedagógiCo, a gente vai começando a trabalhar no sentido de fazer isso. É o que fazemos (BETA, 2017, informação verbal).
\end{abstract}

A partir disso, percebe-se que os professores estão atentos às mudanças que estão ocorrendo no mundo e que isso interfere favoravelmente na maneira que estão ensinando. $E$, caso percebam que a maneira de ensinar não está adequada frente às mudanças da atualidade, estudam uma nova proposta para melhorar o ensino e aprendizagem. Pereira (2015, p. 10) alerta que é preciso "analisar uma nova emersão de jovens que estão adentrando as escolas e exigindo a mudança de todo o panorama educacional". 0 que fica evidente, nesse caso, é que as professoras pesquisadas estão atentas às necessidades desses novos jovens que estão chegando na universidade.

0 que é notório na pesquisa aqui realizada é que as professoras, bem como a equipe toda, perceberam que precisavam pensar em mudanças no plano pedagógico para conseguir atingir as necessidades desses alunos e passar para eles, nas aulas, o conhecimento proposto pelo curso de educação superior em moda. As professoras foram sensiveis ao perceberem a mudança comportamental dos alunos e mostraram-se dispostas a mudar suas aulas para atingir o novo estudante.

\title{
Resultados
}

A partir das entrevistas observou-se que existem alguns fatores que favorecem o compartilhamento do conhecimento entre as professoras. Esses dados foram categorizados e a partir deles desenvolvidos indicadores favoráveis ao compartilhamento do conhecimento. São eles:

- Diálogo das professoras em lugares formais e informais: as professoras conversam no corredor, em sala da aula, nas reuniões de colegiado;

- Pensamento sistêmico: o curso, no geral, está pautado em um pensamento sistêmico e este, além de fazer parte da organização do curso, também é trabalhado na formação dos discentes que terminam o curso com uma visão sistêmica; 
- Reuniões: reuniões facilitam a integração de outros docentes porque são nelas que ocorrem as discussões de todos os projetos;

- Trabalho em equipe: trabalhar em equipe é primordial para as professoras e faz parte da cultura do curso;

- Domínio pessoal: exige que o docente persevere em frequente busca por melhoria e aperfeiçoamento próprio, a fim de expandir sua capacidade pessoal;

- Bom relacionamento entre as professoras: bom relacionamento é primordial para ocorrer o entendimento dos assuntos durante as conversas, discussões, trocas de informações.

Esses são apenas alguns indicadores que se mostraram presentes no processo de compartilhamento do conhecimento. No objeto de estudo em específico observou-se que estas práticas fazem parte do cotidiano e possibilitam a interação e a troca de experiências entre todos os professores do curso de moda e não unicamente entre as professoras da disciplina de modelagem do vestuário.

Observou-se também que não há a escolha de um único método de ensino de modelagem do vestuário, e sim a escolha de trabalhar com vários métodos, o que possibilita ao aluno construir o raciocínio de como se desenvolve um molde a partir do conhecimento de técnicas variadas, e não o conhecimento de um único método e sua técnica.

\section{Considerações finais}

Essa pesquisa iniciou-se com a ideia de que a prática de compartiIhamento do conhecimento ocorria somente com docentes da disciplina de modelagem do vestuário, sendo este um pensamento disciplinar, ou seja, cada área de conhecimento trabalha isolada em disciplinas estanques. Os pensamentos iniciais foram refutados e ampliados, isto porque na unidade de análise estudada ocorre a interdisciplinaridade, isto é, as professoras integram as disciplinas por meio de projetos. Ou seja, o compartilhamento do conhecimento ocorre em todo o curso e não apenas entre disciplinas, isoladamente.

Observou-se, por meio das entrevistas, que as docentes responsáveis pela disciplina de modelagem do vestuário e atuantes no curso de educação superior em moda apresentaram, em suas narrativas, diferentes estratégias para a ação de compartilhar seus conhecimentos e suas informações envolvidos no conceito de gestão da informação e gestão do conhecimento, no intuito de promover a interdisciplinaridade no contexto educacional de ensino superior. Há uma preocupação em ensinar diferentes métodos de modelagem do vestuário aos alunos, fazendo com que desenvolvam a habilidade de criar suas próprias técnicas. 
Logo, frente à perspectiva de investigar o contexto de ensino de modelagem do vestuário, foi possivel entender que a gestão do conhecimento é a estratégia utilizada pelos docentes para o compartilhamento do conhecimento por meio da metodologia de projetos. Os docentes organizam-se em conjunto, trocam informações e experiências e realizam o planejamento e as estratégias de ensino, congruentes entre si, por meio de projetos que integram as disciplinas.

A percepção do universo estudado ao longo de nossa pesquisa e do contexto educacional contemporâneo contribuíram para que defendêssemos a ideia de uma lógica interdisciplinar, ou seja, um trabalho em equipe que resulta não apenas em compartilhar saberes e práticas entre profissionais de uma única área, mas entre profissionais de áreas distintas, a fim de que o conhecimento de todos possa ser ampliado.

A ampliação do conhecimento pode ser feita por meio do compartiIhamento do conhecimento; neste estudo de caso, observou-se por meio das entrevistas que as professoras têm disponibilidade para realizar esta prática, assim como o restante do corpo docente, conforme mencionado nas entrevistas.

0 compartilhamento do conhecimento mostrou-se um meio de integração dos professores para a troca de saberes e reflexão, o que favoreceu a inovação no curso, isto porque se verificou nos relatos das professoras mudanças relevantes no curso. As muitas reflexões feitas pelas professoras durante o compartilhamento do conhecimento geraram um consenso de ideias entre elas que proporcionou as mudanças. Entre elas está a mudança do ensino disciplinar para o ensino interdisciplinar.

Recebido em: 17-03-2018

Aprovado em: 18-04-2018 


\section{NOTA}

${ }^{1}$ Arranjos Produtivos Locais "[...] são aglomerações de empresas localizadas em um mesmo território, que apresentam especialização produtiva e mantêm algum vínculo de articulação, interação, cooperação e aprendizagem entre si e com outros setores locais tais como governo, associações empresariais, instituições de crédito, ensino e pesquisa" (FERREIRA, 2007, p. 65).

\section{REFERÊNCIAS}

ANGELONI, M. T.; MULBERT, A. L Organizações do conhecimento: infraestrutura, pessoas e tecnologia. 2. ed. São Paulo: Saraiva, 2008.

AGUIAR, G. C. O. Cenários constituintes dos cursos superiores de moda no Brasil: conjunturas da década de 80 aos dias atuais. In: CONGRESSO INTERNACIONAL DE MEMÓRIA, DESIGN E MODA, 2., 2015, São Paulo. MODA DOCUMENTA: Museu, Memória e Design. Ano II, n. 1. São Paulo: MIMo/ Estação das Letras e Cores, 2015, p. 249-263. Disponivel em: http://www.modadocumenta.com.br/ wp-content/uploads/2016/01/ANAIS-MD2015_portugues.pdf. Acesso em: 22 ago. 2018.

ALÁRIO, M. A. de S. Os estilistas e a produção de moda. 2007. 200 f. Tese (Doutorado em Sociologia) - Faculdade de Ciências e Letras da Universidade Estadual Paulista, Araraquara, 2007. Disponivel em: https://repositorio.unesp.br/bitstream/handle/11449/106287/alario_mas_dr_arafcl. pdf?sequence=1. Acesso em: 22 ago. 2018.

ALFA. Entrevista I [maio 2017]. Entrevistadora: Maria Helena Ribeiro de Carvalho. Londrina, 2017.1 arquivo .mp3 (40 min.).

ARAUJO, M. de. Tecnologia do vestuário. Lisboa: Fundação Calouste Gulbenkian, 1996.

BARDIN, L Análise de conteúdo. Tradução de Luís Antero Reto e Augusto Pinheiro. São Paulo: Edições 70, 2011.

BARTOL, K.; SRIVASTAVA, A. Encouraging knowledge sharing: the role of organizational reward systems. Journal of Leadership \&t Organizational Studies, v. 9, n. 1, p. 64-76, Summer, 2002.

BETA. Entrevista II [maio 2017]. Entrevistadora: Maria Helena Ribeiro de Carvalho. Londrina, 2017. 1 arquivo .mp3 (40 min.).

CARDOSO, M. E. Trabalho em equipe - uma estratégia de gestão. 1998. Monografia (Curso de Especialização em Gestão Hospitalar) - Universidade Federal de Santa Catarina, Florianópolis, 1998. Disponível em: https://repositorio.ufsc.br/bitstream/handle/123456789/104500/ Trabalho\%20em\%20equipe\%20uma\%20estrat\%C3\%A9gia\%20de\%20gest\%C3\%A30. pdf?sequence=1CtisAllowed=y. Acesso em: 22 ago. 2018.

CARREIRA, S. da S. Análise dos fatores de sucesso das empresas no ramo de confecções na região noroeste do Paraná - "corredor da moda" período 1990 a 2000. 2001. 191 f. (Dissertação) Mestrado em Engenharia de Produção, Universidade Federal de Santa Catarina, Florianópolis, 2001. Disponivel em: https://core.ac.uk/download/pdf/30361323.pdf. Acesso em: 22 ago. 2018.

COSTA, Juliana Aragão Lemes da. 0 ensino de modelagem do vestuário: uma discussão sobre a criação de recursos pedagógicos. 2016. 82 f. Dissertação (Mestrado Profissional em Educação) - Universidade de Brasilia, Brasilia, 2016. Disponivel em: http://repositorio.unb.br/ handle/10482/21820. Acesso em: 22 ago. 2018.

DALKIR, K. Knowledge management in theory and practice. Burlington: Elsevier, 2011.

DAVENPORT, T. H. Ecologia da informação: por que só a tecnologia não basta para o sucesso na era da informação. Tradução de Bernadette Siqueira Abraão. São Paulo: Futura, 1998.

DELGADO, D. Configurações sobre a educação no setor de moda. lara - Revista de Moda, Cultura e Arte, São Paulo, v. 3, n. 3, p. 147-169, dez. 2010. Disponivel em: http://www1.sp.senac.br/hotsites/ blogs/revistaiara/wp-content/uploads/2015/01/IARA_vol3_n3_Completa_2010.pdf. Acesso em: 22 ago. 2018. 
DELTA. Entrevista III [maio 2017]. Entrevistadora: Maria Helena Ribeiro de Carvalho. Londrina, 2017. 1 arquivo .mp3 (40 min.).

FAZENDA, I. C. A. Práticas interdisciplinares na escola. São Paulo: Cortez, 2013.

FERREIRA, A. L Rota de navegação: Desafio Sebrae. 8. ed. Rio de Janeiro: Expertbooks, 2007.

FERREIRA, J. A. A. Arranjos produtivos locais: uma abordagem sobre as relações de poder no APL de metais sanitários do Paraná. Revista Geonorte, v. 4, n. 12, p. 1394-1409, jul. 2013. Disponivel em: http://www.periodicos.ufam.edu.br/revista-geonorte/article/view/1242. Acesso em: 14 ago. 2018.

GAMA. Entrevista IV [maio 2017]. Entrevistadora: Maria Helena Ribeiro de Carvalho. Londrina, 2017. 1 arquivo .mp3 (40 min.).

MARIANO, M. L V. Da construção à desconstrução: a modelagem como recurso criativo no design de moda. 2011. 139 f. Dissertação (Mestrado em Design) - Universidade Anhembi Morumbi, São Paulo, 2011.Disponivel em: $h$ ttp://tede.anhembi.br/tedesimplificado/handle/TEDE/1591. Acesso em: 22 ago. 2018.

MENEZES, M. S.; SPAINE, P. A. de A. Modelagem plana industrial do vestuário: diretrizes para a indústria do vestuário e o ensino-aprendizado. Projética, Londrina, v. 1, n. 1, p. 82-100, dez. 2010 Disponivel em: http://www.uel.br/revistas/uel/index.php/projetica/article/view/7737/6858. Acesso em: 22 ago. 2018.

OLIVEIRA, Ronielton R.; OLIVEIRA, Roniton R.; LIMA, J. B. Reflexão sobre a relação entre a mudança de cultura organizacional e a gestão do conhecimento. Perspectivas em Gestão \&t Conhecimento, João Pessoa, v. 6, n. 1, p. 19-35, jan.jjun. 2016. Disponivel em: http://www.periodicos.ufpb.br/ojs/ index.php/pgc/article/view/23033. Acesso em: 22 ago. 2018.

OLIVEIRA, M. A.; CÂMARA, M. R. G.; BAPTISTA, J. R. V. 0 setor têxtil-confecções do Paraná e seus segmentos regionais especializados: 2000-2004. Revista de Economia, ano 31, v. 33, n. 1, p. 83115, jan./jun. 2007. Disponivel em: https://revistas.ufpr.br/economia/article/view/8548/6019. Acesso em: 22 ago. 2018.

OSÓRIO, L Modelagem: organização e técnicas de interpretação. Caxias do Sul: EDUCS, 2007.

PEREIRA, V. de C. B. Escola do século XIX, professores do século XX e alunos do século XXI: 0 uso do celular em sala de aula na visão dos professores de uma escola pública no município de Campos dos Goytacazes. 2015. 26 f. Monografia (Especialização em Literatura, Memória, Cultura e Sociedade) - Instituto Federal Fluminense, Rio de Janeiro, 2015. Disponivel em: http://bd.centro.iff. edu.br/xmlui/handle/123456789/938. Acesso em: 22 ago. 2018.

PROBST, G.; RAUB, S.; ROMHARDT, K. Gestão do conhecimento: os elementos construtivos do sucesso. Tradução de Maria Adelaide Carpigiani. Porto Alegre: Bookman, 2002.

PROGRAD. Pró-Reitoria de Graduação, 2016. Disponivel em: http://www.uel.br/prograd/. Acesso em: 12 dez. 2017.

RABELO, R. A. et al. Gestão do conhecimento em processos de transformação organizacional: 0 desenvolvimento da intimidade como fator facilitador. Perspectivas em Gestão \&t Conhecimento, João Pessoa, v. 2, n. 1, p. 21-35, jan.jjun. 2012. Disponivel em: http://www.periodicos.ufpb.br/ojs/ index.php/pgc/article/view/12545. Acesso em: 24 ago. 2018.

SENGE, Peter. A quinta disciplina. Tradução de Gabriel Zide Neto. 31. ed. Rio de Janeiro: BestSeller, 2016.

. Escolas que aprendem: um guia da quinta disciplina para educadores, pais e todos que se interessam pela educação. Tradução de Ronaldo Cataldo Costa. Porto Alegre: Artmed, 2005. 
SHINODA, A. C. M. Gestão do conhecimento em projetos: um estudo sobre conhecimentos relevantes, fatores influenciadores e práticas em organizações projetizadas. 2012. Dissertação (Mestrado em Administração) - Faculdade de Economia, Administração e Contabilidade, Universidade de São Paulo, São Paulo, 2012.

SICSÚ, A. B. Elementos preliminares para construção de modelos: a contribuição da gestão do conhecimento para instituições de ensino superior. In: Encontro Nacional de Engenharia de Produção, 27., 2007, Foz do Iguaçu. Anais... Porto Alegre: ABEPRO, 2007.

STEIL, A. V. Estado da arte das definições de gestão do conhecimento e seus subsistemas. Florianópolis: Technical Report, 2007.

TAKEUCHI, H; NONAKA, I. Gestão do conhecimento. Tradução de Ana Thorell. Porto Alegre: Bookman, 2008.

Criação de conhecimento na empresa: como as empresas japonesas geram a dinâmica da inovação. Tradução de Ana Beatriz Rodrigues e Priscila Martins Celeste. Rio de Janeiro: Elsevier, 1997.

TONET, H. C.; PAZ, M. G. T. da. Um modelo para o compartilhamento de conhecimento no trabalho. RAC - Revista de Administração Contemporânea, v. 10, n. 2, p. 75-94, abr.jun. 2006. Disponível em: http://www.scielo.br/pdf/rac/v10n2/a05.pdf. Acesso em: 22 ago. 2018

VASCONCELOS, K. C. de A. et al. Cultura, liderança e compartilhamento do conhecimento organizacional. Revista de Administração FACES Journal, Belo Horizonte, v. 12, n. 1, p. 13-31, jan./ mar. 2013. Disponivel em: http://www.redalyc.org/html/1940/194028663002/. Acesso em: 22 ago. 2018.

VASCONCELOS, M. J. E. de. Pensamento sistêmico: o novo paradigma da ciência. Campinas: Papirus, 2002.

VILLAÇA, N.; CASTILHO, K. Plugados na moda. São Paulo: Anhembi Morumbi, 2006.

YIN, R. K. Estudo de Caso. Planejamento e Métodos. Tradução de Daniel Grassi. Porto Alegre: Bookman, 2005.

ZETA. Entrevista V [maio 2017]. Entrevistadora: Maria Helena Ribeiro de Carvalho. Londrina, 2017. 1 arquivo .mp3 (40 min.). 